\title{
Vértices geodésicos, elementos físicos del mapa sobre el territorio
}

Fernando Barranco Molina, ingeniero técnico en Topografía, Dpto. de Ingeniería de Diseño y Proyectos, Universidad de Huelva

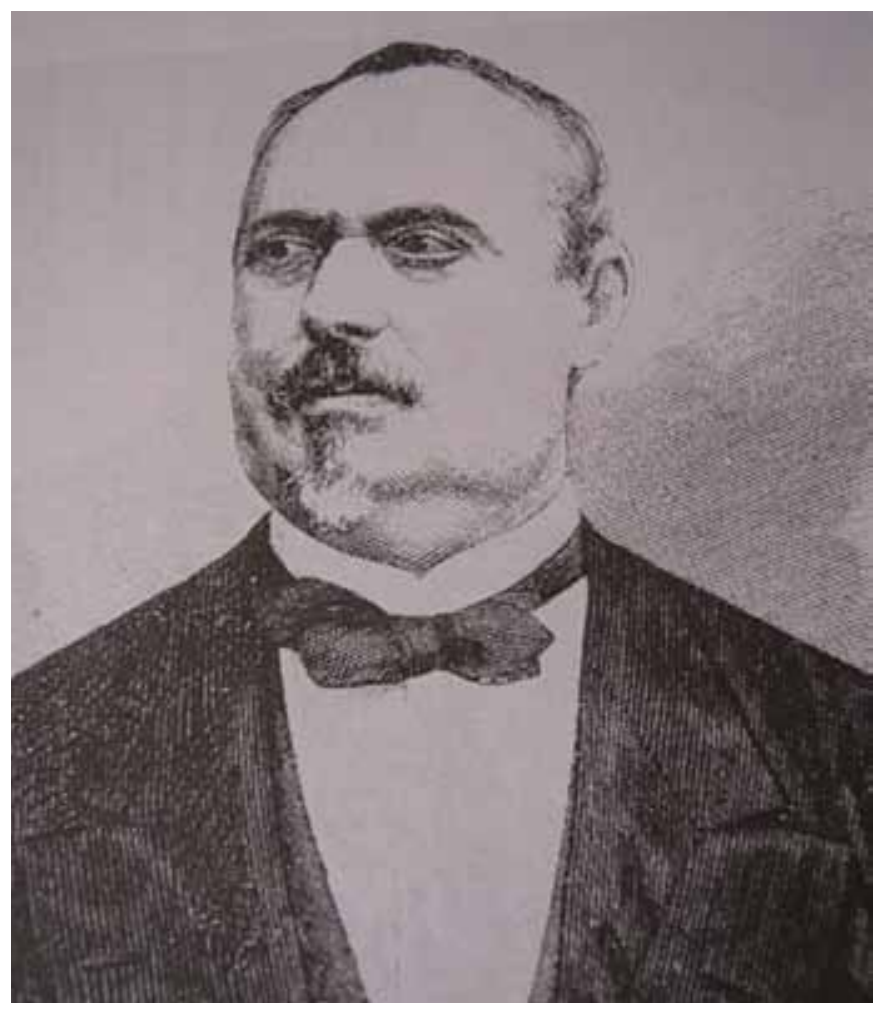

Francisco Coello de Portugal y Quesada, autor del primer mapa de carácter científico de España. Fuente: MARTíN LÓPEZ, 1999

"Los cortesanos, sin salir de sus aposentos ni de los umbrales de la corte, se pasean por todo el mundo, mirando un mapa, sin costarles blanca, ni padecer calor ni frío, hambre, ni sed; pero nosotros, los caballeros andantes verdaderos, al sol, al frío, al aire, a las inclemencias del tiempo, de noche y de dia, a pie y a caballo, medimos toda la tierra con nuestros mismos pies..."

Miguel de Cervantes Saavedra Don Quijote de la Mancha. Segunda parte, Capítulo VI (1730)

Un vértice geodésico es una señal permanente que se materializa sobre el terreno y que forma parte de una red de triángulos cuyas coordenadas se han calculado con la mayor exactitud y precisión posible. Dicha red de triángulos da la vuelta a todo el globo terráqueo, es decir que el mundo entero está comunicado a través de los vértices geodésicos y con el mismo sistema de coordenadas.

La señal por lo general es un cilindro de aproximadamente 1,20 $\mathrm{m}$ de altura montado sobre un dado de hormigón y pintado de blanco aunque también puede ser un prisma cuadrangular. Encima de esta señal se instala el instrumento topográfico para ha- cer las mediciones necesarias. Los vértices están situados en los lugares más altos y despejados y con una gran visión paisajistica

Se catalogan en vértices de $1^{\text {er }}$ orden, de $2^{\circ} y$ de $3^{\text {er }}$. La red de $1^{\circ}$ orden es la de más precisión y está reseñada en los mapas con un pequeño triángulo y un punto en el centro que es el signo convencional. Existen algunos denominados REGENTES, que son las siglas de Red Geodésica Nacional por Técnicas Espaciales, de altísima precisión.

Con el objetivo de proteger y mantener los vértices, el 12 de marzo de 1975 se promulgó una Ley de Señales Geodésicas y Geofísicas. En ellos existe una placa que indica el significado de esta señal y avisa de que su destrucción está penada por la ley.

En 1842 se crea en España la Escuela de Estado Mayor del Ejército empezándose a tener personal preparado científicamente y aparece también una gran figura de la cartografía mundial: Francisco Coello de Portugal y Quesada. Él realizó todos los mapas de España que acompañan al Diccionario Geográfico y Estadístico de Madoz y que forman el Atlas de España y sus posesiones de ultramar. Esta cartografía ha sido la mejor existente en nuestro país hasta la aparición del Mapa Topográfico Nacional. Coello fue el redactor de la Ley de Medición del Territorio que aprobaron las Cortes españolas el 5 de junio de 1859 en la que ya se establecian las triangulaciones geodésicas de primer y segundo orden. Coello fue sin duda el gran cartógrafo de la modernidad.

El testigo lo recoge otro ilustre militar, Carlos Ibáñez e Ibáñez de Ibero, marqués de Mulhacén, fundador del Instituto Geográfico encargado de la realización de todos los trabajos topográficos y cartográficos de España, teniendo encomendado la realización del Mapa Topográfico Nacional a Escala 1:50.000, que llevaba implícito en primer lugar la implantación de una red geodésica, aunque ésta ya se había iniciado unos años antes.

Los lugares donde están situados estos hitos son generalmente muy altos y por sólo citar algunos donde la historia haya dejado su huella, tenemos el vértice San Ginés que tiene una altitud de 869 metros sobre el nivel del mar y está en las cercanias de Aracena (Huelva). El vértice está situado en el cerro del mismo nombre junto a las ruinas de la antigua ermita de San Ginés, patrón que fue de Aracena. En este lugar se celebraban unas peculiares fiestas en 
El primer mapa con Andalucía para todo el territorio: la denominación de Andalucia aparece adscrita a todo el territorio en un mapa francés de 1810: Assemblage des feuilles de la carte d'Andalousie:

Construite au 1:100.000 D'après les ordres de S.E. le Mal. Duc de Dalmatie Major Général / [Bureau Topographique de l'Armée d'Espagne]

Service Historique de la Défense, Département de l'armée de Terre (Vincennes). 6M L12 B2 1101

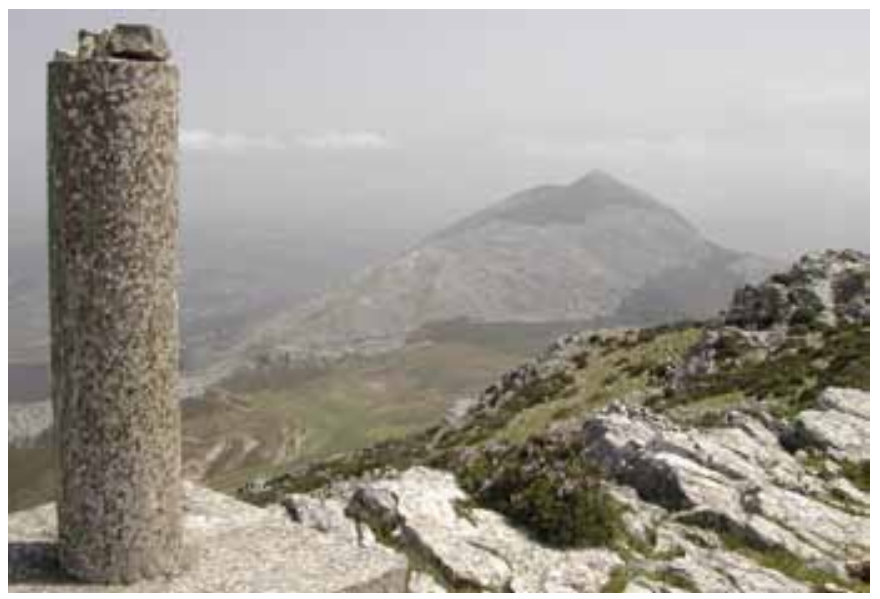

Vértice geodésico de La Huma (Antequera, Málaga) desde donde se domina el valle del Guadalhorce. Foto: Gonzalo Moreno

honor del santo donde se ofrecian a los pobres pan, queso y vino y que, por culpa de la embriaguez de los paisanos, fue prohibida en el año 1777, aunque una tradición tan arraigada entonces era muy dificil de eliminar y se volvieron a celebrar en años sucesivos. Con el tiempo se fue perdiendo y hoy sólo quedan las ruinas y el recuerdo y un vértice geodésico desde el cual se divisa un maravilloso paisaje.

El vértice Umbría, situado encima de la torre de Almenara de Punta Umbria, es un regente. Esta torre fue construida en el año 1614 por orden del Rey Felipe III para defender la costa de los "enemigos de nuestra Santa Fe".

El vértice Almonaster está construido junto a las ruinas de la antigua ermita de San Cristóbal. Desde el vértice Ilamado Virgen de la Peña, junto a la ermita de la virgen del mismo nombre, en Puebla de Guzmán, se divisa media provincia de Huelva y medio Alentejo portugués. El conocido como Padre Caro está junto a las antiguas minas Peña del Hierro, donde actualmente la NASA realiza sus experimentos. En plena sierra está el denominado Ballesteros, nombre que recibe en honor del célebre general del ejército español que libró a nuestra sierra de los abusos y saqueos de los franceses. Desde el vértice Ballesteros podemos ver volar las colonias de buitres negros que habitan por estos parajes y que es de los pocos sitios donde se pueden ver ya.

En la costa, en lo más alto de las dunas existentes entre Mazagón y Matalascañas, hay otro vértice llamado Bombo o Asperillo

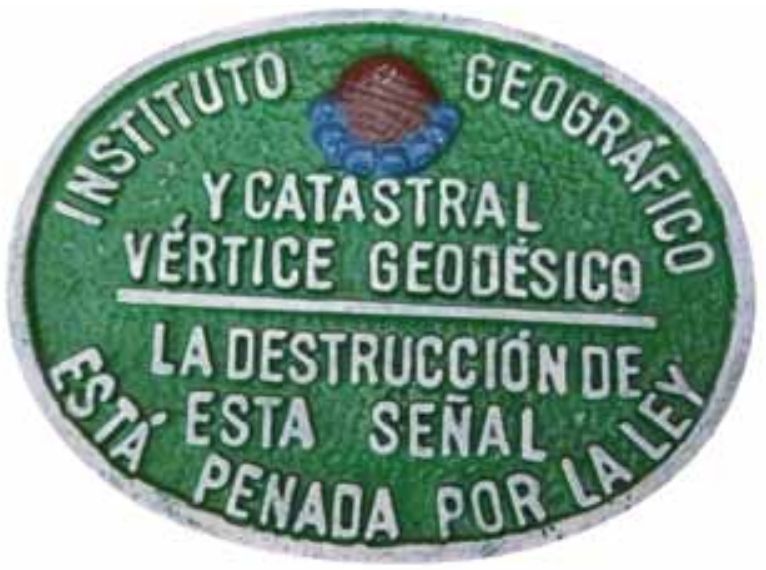

Placa colocada en todos los vértices geodésicos. Foto: Fernando Barranco Molina

desde el cual se ve toda la costa de Huelva y hasta incluso la costa de Cádiz y la de Portugal. Téngase en cuenta que estamos situados junto al mar pero a una altura superior a los 100 metros, son las dunas costeras más altas de Europa.

Al norte de la población de Alosno hay un cerro que alberga unas importantes ruinas mineras del 2.500 a. de C. Alli está el vértice Juré. En Calera de León, encima del Monasterio de N. ${ }^{\text {a }}$. ${ }^{a}$ de Tentudia, está el vértice Tentudia, construido con un diseño diferente adornado con tejas para que no destaque demasiado del conjunto monumental.

Los vértices geodésicos, por tanto, son los elementos matemáticos de la estructura de todo mapa, que el ilustre estadista Gaspar Melchor de Jovellanos, refiriéndose a ellos, decia "Los Mapas hacen florecer las provincias y aumentar el verdadero esplendor de las naciones".

\section{Bibliografía}

BARRANCO MOLINA, F. (1998) Recóndita Huelva. Huelva: Caja Rural de Huelva 1998

MARTíN LÓPEZ J. (1999) Francisco Coello: su vida y su obra. Madrid: Ministerio de Fomento, Centro Nacional de Información Geográfica, 1999 MARTín LÓPEZ J. (2002) Historia de la Cartografía y de la Topografía. Madrid: Ministerio de Fomento, Centro Nacional de Información Geográfica, 2002 MARTÍNEZ UTESA, M. C. (1995) Ciencia y milicia en el siglo XIX en España: El general Ibáñez e Ibáñez de Ibero. Madrid: Instituto Geográfico Nacional, 1995 